on subdisciplines, too many "drudgery hours", and lack of regular assessments. He urged that African universities and nations do more strategic planning, carried out in a way that strikes a responsive chord among the people. Educational programs, he said, need to be directed toward acceptable goals.

According to Prof. Mokoena, there is a need to provide high-quality, relevant programs with clearly defined aims and objectives. The programs should emphasize mastery of the use of instrumentation, reduce staff and student time spent in rote learning, and provide for the needs of majors as well as general interest or preprofessional students. The programs should especially include project-based teaching and work experience assignments. There also should be opportunity for distance learners and adults to study chemistry. The structure of the program should prepare students for conventional and applied course options.

\section{The Role of the Chemical Industry in Ensuring Sustainable Development in Africa}

Dr. M. Booth, a member of IUPAC's Committee on Chemistry and Industry (COCI) outlined operations of the chemical industry in sub-Saharan Africa. He explained that from a global perspective the chemical industry in Africa is small, operating mainly in South Africa, Zimbabwe, Ghana, Zambia, Nigeria, and Egypt.

The primary manufacturing sectors are explosives, fertilizers, insecticides, petrochemicals, and polymers. Management practice standards, e.g., the Responsible Care program, are applied in the areas of health and safety, storage and distribution, transportation, waste management and pollution control, community awareness and emergency response, and product stewardship.

Dr. Booth noted that the firm AECI has recently opened new explosives factories in two African countries. These new enterprises have created new jobs for chemical professionals. It will be important to educate and hire as many Africans as possible for these new jobs, rather than to import personnel from elsewhere.

Dr. Booth suggested that ways need to be developed to improve the image of chemistry through government, industry, and societal activities. Government must provide clear, unambiguous policies, implementable legislation, and fair enforcement. Industry must care for the health and safety of the workers, be mindful of product stewardship, and be ready to communicate hazards. Consumers must learn to read and understand cautionary labels, use chemicals as directed, and dispose of waste chemicals safely.
Special challenges for Africa lie in existing international legal obligations and treaties, poor ambient environmental quality, development of sustainable consumption and cleaner production, and finding eco-efficient uses of natural resources.

Existing international agreements regulating movement of hazardous waste across international boundaries are a challenge to African countries. No national legislation on the subject exists in South Africa or in Africa generally. Moreover, additions to the Montreal Protocol are making it increasingly difficult for economically disadvantaged nations to conform. African countries are having difficulty implementing the Protocol on Informed Consent (PIC) Convention on the use of pesticides, the Protocol on Pesticides (POP) Convention norms regarding organic pesticides, and standards for compliance to global climate change rules. Africa is one of the most economically vulnerable regions, and therefore it is least able to deal with new or established regulations. African industry needs to participate more in the setting of international protocols.

Africa must move its orientation in environmental practices from environmental protection to sustainable development. This shift in orientation will require careful environmental stewardship, social development, and economic growth. A priority goal will be to begin to eliminate poverty through the fulfillment of basic household needs, such as provision of safe water supplies. This problem can be addressed through sustainable consumption, i.e., through minimization of waste and recycling of chemical materials.

Dr. Booth noted that it is important to share expertise and experience to develop uniquely African solutions to support African industrial development. The challenges in Africa will require replacement of obsolete chemical processes with new, "green" technology. According to one estimate, there is much room for growth since the African economy is on average only about $20 \%$ technology driven.

Prof. L. Diop of Senegal reminded the participants that Africa has plenty of natural resources, e.g., coal, minerals, and diamonds. He noted that, even though the image of chemistry has suffered because of pollutants coming from industry, and the field inherits a lot of the blame for pollution resulting from the generation of energy, the chemical industry is nevertheless at the very heart of development. Prof. Diop suggested that Africa should concentrate on small technology for local consumption as a way of building grass-roots markets. Also, Africa should look as an example to the efforts made by Asia in the 1960s. Greater cooperation is needed in setting up joint regional research and production centers. The participants agreed that it is as important in Africa as it is in other regions of the world to publicize the positive aspects of chemistry. 